\title{
Determination and optimization of flavonoid and extract yield from brown mango using response surface methodology.
}

\begin{abstract}
The optimum extraction conditions to obtain the highest flavonoid content and extract yield from Mangifera pajang pericarp (MPP) were analyzed using response surface methodology (RSM). A full factorial central composite design was used to investigate the effects of ethanol concentration $(20-80 \%)$, temperature $\left(30-65^{\circ} \mathrm{C}\right)$ and liquid to solid ratio $(20-50 \mathrm{~mL} / \mathrm{g})$ on the recovery of extract yield and flavonoids. A second order polynomial model produced a satisfactory fitting of the experimental data with regard to extract yield ( $2=0.9890$, $\mathrm{p}<$ $0.0001)$ and flavonoids $(\mathrm{R} 2=0.9652, \mathrm{p}<0.0001)$. The optimum conditions to obtain higher extract yield, were $54 \%, 50^{\circ} \mathrm{C}$, and $42.4 \mathrm{~mL} / \mathrm{g}$, while for flavonoids were $68 \%, 57^{\circ} \mathrm{C}$, and $20.2 \mathrm{~mL} / \mathrm{g}$, respectively. The experimental values agreed with those predicted with $99 \%$ and 96\% confidence interval for extract yield and flavonoids respectively. This indicates the suitability of RSM in optimizing the extraction of flavonoids and extract yield from MPP.
\end{abstract}

Keyword: Flavonoid content; Mangifera pajang; Optimisation 